Applied nutritional investigation

\title{
Detection and treatment of medical inpatients with or at-risk of malnutrition: Suggested procedures based on validated guidelines
}

\author{
Lisa Bounoure Ph.D. ${ }^{a}$, Filomena Gomes R.D., Ph.D. ${ }^{a}$, Zeno Stanga M.D. ${ }^{\text {, }}$ \\ Ulrich Keller M.D. ${ }^{\mathrm{c}}$, Rémy Meier M.D. ${ }^{\mathrm{d}}$, Peter Ballmer M.D. ${ }^{\mathrm{e}}$, Rebecca Fehr R.D. ${ }^{\mathrm{a}}$, \\ Beat Mueller M.D. ${ }^{\text {a }}$, Laurence Genton M.D. ${ }^{\mathrm{f}}$, Pauline Coti Bertrand M.D. ${ }^{\mathrm{g}}$, \\ Kristina Norman Ph.D. ${ }^{h}$, Christoph Henzen M.D. ${ }^{i}$, Alessandro Laviano M.D. ${ }^{j}$, \\ Stephan Bischoff M.D., Ph.D. ${ }^{\text {, }}$, Stéphane M. Schneider M.D. ${ }^{1}$, Jens Kondrup M.D. ${ }^{\text {, }}$ \\ Philipp Schuetz M.D., M.P.H. ${ }^{\mathrm{m}, *}$ Members of the Working Group
}

${ }^{a}$ Department of Endocrinology, Diabetes and Clinical Nutrition, University Department of Internal Medicine, Cantonal Hospital Aarau, Aarau, Switzerland

${ }^{\mathrm{b}}$ Department of Endocrinology, Diabetes and Clinical Nutrition, University Hospital and University of Bern, Bern, Switzerland

${ }^{\mathrm{c}}$ Endocrine Practice, University of Basel, Basel, Switzerland

${ }^{\mathrm{d}}$ Gastrocenter Obach, Solothurn, Switzerland

${ }^{\mathrm{e}}$ Department of Medicine, Canton Hospital Winterthur, Winterthur, Switzerland

${ }^{\mathrm{f}}$ Clinical Nutrition, University Hospitals of Geneva, Geneva, Switzerland

${ }^{\mathrm{g}}$ University Hospital Lausanne (CHUV), Switzerland

${ }^{\mathrm{h}}$ Charité Medical University Berlin, Berlin, Germany

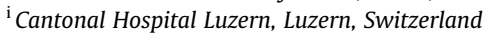

${ }^{\mathrm{j}}$ Department of Clinical Medicine, Sapienza University, Rome, Italy

${ }^{\mathrm{k}}$ University of Hohenheim, Stuttgart, Germany

${ }^{1}$ University Hospital, University of Nice Sophia-Antipolis, Faculty of Medicine, Nice, France

${ }^{\mathrm{m}}$ University Hospital Rigshospitalet and University of Copenhagen, Copenhagen, Denmark

\section{A R T I C L E I N F O}

\section{Article history:}

Received 23 September 2015

Accepted 25 January 2016

\section{Keywords:}

Procedures

Clinical algorithm

Acute disease

Disease-related malnutrition

Nutritional therapy

Medical wards

\begin{abstract}
A B S T R A C T
Objective: Despite the high prevalence of malnutrition in the general inpatient population, there is a lack of knowledge in regard to detecting disease-related malnutrition and implementing nutritional support. Our aim was to suggest practical procedures for screening and treating malnourished or at-risk patients hospitalized in medical wards, thereby fostering a straightforward implementation of nutritional therapy independent of the underlying disease and comorbidities. Methods: A working group of experts in clinical nutrition selected and analyzed published diseasespecific European Society for Clinical Nutrition and Metabolism (ESPEN) guidelines relevant for our aim. Eight questions in population, intervention, control, outcome format were defined to cover topics such as screening, nutritional targets, and routes of feeding. Individual studies were extracted from the guidelines by applying inclusion and exclusion criteria targeting the heterogeneous population of medical inpatients with or at-risk of disease-related malnutrition. We used those studies as evidence, as well as recommendations from the selected ESPEN guidelines, to formulate answers to the questions. Final agreement with the statement was obtained by consensus of the whole working group.
\end{abstract}

L.B. and F.G. contributed equally to this study. We thank warmly all member of
the expert working group for their contribution to the development of these
suggested procedures. The working group (see Acknowledgment section)
selected relevant ESPEN disease specific guidelines, defined topics of interest,
and developed the clinical questions. L.B. and F.G. extracted the studies from
each selected guidelines after defining the inclusion and exclusion criteria
applying to participants, outcomes, and study design; compiled the recom-
mendations of the selected ESPEN guidelines; analyzed the extracted evidence,
formulated the statements for each question, and drafted the manuscript. All members of the working group expressed their level of agreement with each statement. All authors reviewed and approved the manuscript. P.S. has primary responsibility for final content. P.S. is supported by the Swiss National Science Foundation (SNSF Professorship, PP00 P3_150531/1) and the Research Council of the Kantonsspital Aarau, Switzerland (1410.000.044). Nestle Suisse SA supported the research project with an unrestricted research grant. Abbott AG provided a fellowship grant for the development of nutritional guidelines.

* Corresponding author. Tel.: +41 (0)62 838 9524; fax: +41 (0)62 8386945 E-mail address: Philipp.Schuetz@unibas.ch (P. Schuetz). 
Results: Procedures on how to provide integrated nutritional therapy (oral, enteral, and parenteral) to a heterogeneous patient population were suggested, including how to identify malnourished or at-risk patients, nutrient targets, choice of feeding route, monitoring, and assessment of patients. We also developed a simple algorithm to facilitate the implementation of a nutritional care plan for the general medical inpatient population.

Conclusion: By compiling evidence and recommendations from disease-specific guidelines, we were able to suggest a nutritional strategy applicable to large and heterogeneous group of malnourished or at-risk patients admitted to hospitals. A large randomized controlled trial is currently investigating whether this strategy improves clinical outcomes of patients.

(c) 2016 Elsevier Inc. All rights reserved.

\section{Introduction}

Patients admitted to medical wards of hospitals, for instance after an acute exacerbation of a chronic condition, are at high risk to have or develop disease-related malnutrition (DRM) resulting from loss of appetite, poor nutritional intake, and disease-related catabolism [1,2]. If untreated, DRM ultimately leads to significant loss of lean and adipose tissues and affects the function and recovery of multiple organ systems [3]. Among hospitalized patients, the prevalence of DRM is estimated between $20 \%$ and $55 \%$, with about $20 \%$ of patients affected in Switzerland [4-7]. Hospitalized elderly patients are particularly vulnerable to develop DRM as a consequence of preexisting decreased lean body mass and impaired intake of protein, energy, and fluids [8]. DRM in turn has profound effects on disease course and recovery $[9,10]$. Several clinical studies have linked DRM to a higher morbidity, mortality, risk of infection, longer stay in the hospital, and higher costs [11]. In addition, several randomized controlled trials (RCTs) found beneficial effects associated with nutritional therapy in the malnourished inpatient population. In fact, a recent meta-analysis focusing on nutritional support in the medical inpatient population found nutritional interventions to be associated with high intake of energy and protein and an increase in body weight [12]. Risk for unplanned readmission after hospital discharge was significantly decreased as was length of stay in the malnourished population.

Current guidelines published by the European Society for Clinical Nutrition and Metabolism (ESPEN) provide primarily recommendations for nutritional therapy specific to particular organ dysfunctions and medical specialty (e.g. liver, oncology, and geriatrics). Yet, those recommendations are often neglected and or not implemented in the large and highly heterogeneous medical inpatient population of medical wards. This may be one of the reasons why, in many medical wards of hospitals, no systematic screening and nutritional therapy programs are currently in place, which contributes to the alleged undertreatment of patients with this condition. A study from 2010, including patients admitted to the departments of internal medicine of seven Swiss hospitals during a 3 years period, showed that among those with a strong indication for nutrition therapy, only $70 \%$ obtained nutritional interventions.

We created a multiprofessional working group composed of experts in clinical nutrition, used current ESPEN guidelines, and the research findings they were built on, to establish a consensus on how to provide nutritional therapy to the heterogeneous malnourished or at-risk medical inpatient population. We detail our rationale and supporting evidence for our suggestions and present them as an algorithm to enable easy and quick decision making for nutritional therapy for general medical inpatients with or at-risk of DRM. The present study was carried out in preparation for a large-scale, Swiss-wide, multicenter RCT (https://clinicaltrials.gov/ct2/show/NCT02517476) in a mixed internal medicine population, where the proposed algorithm is currently being validated.

\section{Methods and materials}

A working group of experts in clinical nutrition was formed (see Acknowledgment section). During a workshop that took place in Basel, Switzerland, on February 21, 2014, a subworking group selected ESPEN guidelines specific to diseases and medical specialties (e.g. liver disease and oncology) to be used as a source of supporting evidence relevant to the patient population of general medical inpatients (Appendix A available online at www.nutritionjrnl.com). Guidelines for the geriatric population were also considered since a large part of malnourished or at-risk patients in medical wards of hospitals are elderly (i.e. over 75 y old). All guidelines we selected were updated for the last time in 2006 and 2009 (guidelines for enteral and parenteral nutrition, respectively). The subworking group also defined topics of interest to be covered in the suggested procedures (such as screening method, energy, protein, micronutrient and other nutritional targets, route of feeding). Eight clinical questions in population, intervention, control, outcome format were developed to address those topics.

In a second step, we defined inclusion and exclusion criteria applying to participants, outcomes and study design to explore the evidence behind the selected ESPEN guidelines (Appendix B available online at www.nutritionjrnl. com). Thereafter, we screened the abstracts of the studies found in the ESPEN guidelines and selected those that met our inclusion criteria and provided answers to our questions. The years of publication (1982-2007), design, number, and main diagnostic of patients of each included study are reported in Table 1. Recommendations applying to at-risk or malnourished patients found in the selected ESPEN guidelines and providing answers to each of our clinical questions were also extracted and are presented in Appendix A available online at www. nutritionjrnl.com. For each clinical question, we formulated statements based on 1) the analysis of the studies we selected from the ESPEN guidelines (Table 1), and 2) the recommendations found in those guidelines (Appendix A available online at www.nutritionjrnl.com).

Statements were presented in a table (Table 2) that was sent by email to all members of the working group. The members were asked to express their level of agreement with each statement by choosing between a "strong" (i.e. we recommend or "should") or "weak" (we suggest or "may") agreement and by providing a rationale supporting their opinion. After collecting all agreements, statements were adapted according to their associated predominant level and a final consensus procedure on the detection and treatment of malnutrition in medical inpatients was suggested. We developed ultimately a nutrition algorithm to display our conclusions in a graphical format (Fig. 1).

\section{Results}

Indication

Question 1. Is the Nutritional Risk Screening 2002 (NRS) an appropriate tool to identify inpatients who are malnourished or at risk for malnutrition, and predict positive outcome if followed by nutritional support, when compared to other validated methods?

Although there is no universally accepted definition of malnutrition, several nutritional screening and assessment tools have been developed to detect the risk of DRM and/or existing DRM in hospitalized patients. 
Table 1

Studies extracted from selected ESPEN guidelines and used to answer each clinical question

\begin{tabular}{|c|c|c|c|c|}
\hline $\begin{array}{l}\text { Search } \\
\text { question }\end{array}$ & Source, year & Studies included (author, year) & Study design & Participants (main diagnostic, $\mathrm{N}$ ) \\
\hline \multirow[t]{2}{*}{ Question 1} & $\begin{array}{l}\text { ESPEN Guidelines for } \\
\text { Nutrition Screening 2002, } 2003\end{array}$ & Kondrup et al., 2003 & Retrospective analysis & Various acute illnesses, 8944 \\
\hline & $\begin{array}{l}\text { ESPEN Guidelines for } \\
\text { Nutrition Screening 2002, } 2003\end{array}$ & Johansen et al., 2003 & $\mathrm{RCT}$ & Various diagnostics, 212 \\
\hline \multirow[t]{6}{*}{ Question 2} & $\begin{array}{l}\text { ESPEN Guidelines for } \\
\text { Nutrition Screening 2002, } 2003\end{array}$ & Johansen et al., 2003 & RCT & Various diagnostics, 212 \\
\hline & ESPEN Guidelines on & Mendenhall 1993 & Non-randomized trial & Severe alcoholic hepatitis, 273 \\
\hline & Enteral Nutrition: Liver disease, 2006 & Kerns 1992 & $\mathrm{RCT}$ & Alcoholic liver disease, 31 \\
\hline & ESPEN Guidelines on Enteral & Heymsfield 1989 & Non-randomized trial & Congestive heart failure, 8 \\
\hline & Nutrition: Cardiology and Pulmonology, 2006 & Ferreira 2012 & Systematic review & Obstructive pulmonary disease, 325 \\
\hline & $\begin{array}{l}\text { ESPEN Guidelines on Enteral } \\
\text { Nutrition: Non-surgical oncology, } 2006\end{array}$ & Ollenschläger 1992 & RCT & Acute leukemia, 29 \\
\hline \multirow[t]{8}{*}{ Question 3} & $\begin{array}{l}\text { ESPEN Guidelines on Enteral } \\
\text { Nutrition: Adult Renal Failure, } 2006\end{array}$ & Schneeweiss 1990 & Non-randomized trial & Acute renal failure, 86 \\
\hline & ESPEN Guidelines on Enteral & Knox 1983 & Observational study & Cancer, 200 \\
\hline & Nutrition: Non-surgical oncology, 2006 & Dempsey 1984 & Observational study & Gastrointestinal cancer, 173 \\
\hline & $\begin{array}{l}\text { ESPEN Guidelines on Enteral } \\
\text { Nutrition: Gastroenterology, } 2006\end{array}$ & Klein 1988 & Observational study & Ulcerative colitis, 8 \\
\hline & $\begin{array}{l}\text { ESPEN Guidelines on Enteral } \\
\text { Nutrition: Pancreas, } 2006\end{array}$ & Dickerson 1991 & Observational study & Acute pancreatitis, 48 \\
\hline & ESPEN Guidelines on Parenteral & John, W.J., 1989 & Non-randomized trial & Alcoholic hepatitis, 20 \\
\hline & Nutrition: Hepatology, 2009 & Madden 1999 & Non-randomized trial & Alcoholic hepatitis, 141 \\
\hline & $\begin{array}{l}\text { ESPEN Guidelines on Enteral } \\
\text { Nutrition: Cardiology and Pulmonology, } 2006\end{array}$ & Poehlman 1994 & Non-randomized trial & Congestive heart failure, 60 \\
\hline \multirow[t]{6}{*}{ Question 4} & $\begin{array}{l}\text { ESPEN Guidelines on Enteral } \\
\text { Nutrition: Gastroenterology, } 2006\end{array}$ & Klein 1988 & Observational study & Ulcerative colitis, 8 \\
\hline & $\begin{array}{l}\text { ESPEN Guidelines on Enteral Nutrition: } \\
\text { Wasting in HIV and other chronic } \\
\text { infectious diseases, } 2006\end{array}$ & Selberg 1995 & Non-randomized trial & HIV, 6 \\
\hline & ESPEN Guidelines on Enteral & Bunout 1989 & $\mathrm{RCT}$ & Alcoholic liver disease, 36 \\
\hline & Nutrition: Liver disease, 2006 & Calvey 1985 & RCT & Alcoholic hepatitis, 64 \\
\hline & ESPEN Guidelines on Parenteral & Swart 1989 & Non-randomized trial & Liver cirrhosis, 8 \\
\hline & Nutrition: Hepatology, 2009 & Nielsen 1993 & Observational study & Alcoholic liver cirrhosis, 37 \\
\hline \multirow[t]{5}{*}{ Question 5} & $\begin{array}{l}\text { ESPEN Guidelines on Enteral } \\
\text { Nutrition: Pancreas, } 2006\end{array}$ & Du 2003 & RCT & Acute pancreatitis, 84 \\
\hline & $\begin{array}{l}\text { ESPEN Guidelines on Parenteral } \\
\text { Nutrition: Pancreas, } 2009\end{array}$ & Siriwardena 2007 & $\mathrm{RCT}$ & Acute pancreatitis, 43 \\
\hline & ESPEN Guidelines on Enteral Nutrition: & Fearon 2003 & $\mathrm{RCT}$ & Cancer, 200 \\
\hline & Non-surgical oncology, 2006 & Bruera 2003 & $\mathrm{RCT}$ & Cancer, 60 \\
\hline & & Gogos 1998 & $\mathrm{RCT}$ & Cancer, 30 \\
\hline \multirow[t]{6}{*}{ Question 6} & $\begin{array}{l}\text { ESPEN Guidelines on Enteral } \\
\text { Nutrition: Geriatrics, } 2006\end{array}$ & Milne 2002 & Systematic review & $\begin{array}{l}\text { Geriatrics, } 2464 \text { (of whom } 1623 \\
\text { unwell, } 854 \text { undernourished) }\end{array}$ \\
\hline & & Milne 2006 & Meta-analysis & Geriatrics, 9187 \\
\hline & & Potter 2001 & $\mathrm{RCT}$ & Various diagnostics, geriatrics, 381 \\
\hline & & McEvoy 1982 & RCT & Various diagnostics, geriatrics, 51 \\
\hline & & Volkert 1996 & RCT & Various diagnostics, geriatrics, 46 \\
\hline & $\begin{array}{l}\text { ESPEN Guidelines on Enteral Nutrition: } \\
\text { Cardiology and Pulmonology, } 2006\end{array}$ & Saudny-Unterberger 1997 & $\mathrm{RCT}$ & $\begin{array}{l}\text { Acute Exacerbation of Chronic Obstructive } \\
\text { Pulmonary Disease, } 33\end{array}$ \\
\hline Question 7 & $\begin{array}{l}\text { ESPEN Guidelines on Enteral } \\
\text { Nutrition: Pancreas, } 2006\end{array}$ & Pandey 2004 & $\mathrm{RCT}$ & Acute pancreatitis, 28 \\
\hline Question 8 & $\begin{array}{l}\text { ESPEN Guidelines on Parenteral } \\
\text { Nutrition: Pancreas, } 2009\end{array}$ & Marick 2004 & Meta-analysis & Acute pancreatitis, 263 \\
\hline
\end{tabular}

RCT, randomized controlled trial

The NRS is a nutrition screening tool that includes the evaluation of nutritional risk, disease severity and age of the patient. It was developed based on a retrospective analysis of 128 RCTs of nutritional therapy versus no therapy on clinical outcome in hospitalized patients [13]. This analysis suggested that the NRS was able to identify patients at risk of malnutrition and to determine who would or would not benefit from nutritional support, being a score of at least 3 indicative of a increased risk of DRM and potential benefits from nutritional interventions. The trials included in the study were performed in clinically heterogeneous groups of patients including surgical, critically ill, and long-term care patients. Following this retrospective analysis, a prospective RCT focusing on 212 patients, predominantly hospitalized on medical wards (68\% of the included patients) was conducted. The NRS enabled to identify individuals at risk of DRM, yet the intervention did not result in significant effects on complications rate, length of hospital stay or quality of life (QoL), questioning therefore the capacity of the NRS to predict positive outcomes following nutritional therapy in the medical inpatient population [14].

For the hospital setting, ESPEN recommends using the NRS to determine the risk of malnutrition within $48 \mathrm{~h}$ postadmission [15]. Most disease and organ-specific selected guidelines, however, do not provide recommendation on the choice of malnutrition screening and assessment tools, rather relying on weight loss or BMI to identify patients at risk of malnutrition. Those parameters are also commonly used to diagnose DRM. 
Table 2

Consensus opinion on nutritional therapy for general patients in medical wards of hospitals

\begin{tabular}{|c|c|c|}
\hline Topics & Recommendations & Agreement \\
\hline \multirow[t]{2}{*}{ Indication } & $\begin{array}{l}\text { The NRS should be used in medical wards to identify patients at risk of malnutrition (i.e. with a score of at } \\
\text { least } 3 \text { points), within } 48 \text { h post-hospital admission. A full nutritional assessment (including an in-depth evaluation } \\
\text { of anthropometric, biochemical, clinical, and dietary information) should be performed in patients with an NRS } \geq 3 \text { to } \\
\text { determine if the patient is truly malnourished, to understand the causes of malnutrition and thus to support the } \\
\text { development of a tailored nutrition care plan. }\end{array}$ & Strong \\
\hline & $\begin{array}{l}\text { Nutritional therapy should be considered in malnourished or at-risk medical inpatients for at least } 5 \text { to } 7 \mathrm{~d} \text { in } \\
\text { order to improve nutrition-related outcomes. }\end{array}$ & Strong \\
\hline \multirow{4}{*}{$\begin{array}{l}\text { Energy and protein } \\
\text { requirements }\end{array}$} & REE should be individually measured by indirect calorimetry. & Strong \\
\hline & When indirect calorimetry cannot be used, we suggest calculating REE with the body weight-adjusted & Weak \\
\hline & $\begin{array}{l}\text { Intakes of protein increased to at least } 1.2 \mathrm{~g} / \mathrm{kg} \mathrm{BW} / \mathrm{d} \text { should be provided to correct or prevent protein malnutrition } \\
\text { in malnourished or at-risk medical inpatients. }\end{array}$ & Strong \\
\hline & $\begin{array}{l}\text { We suggest lowering the protein intake to } 0.8 \text { to } 1 \mathrm{~g} / \mathrm{kg} \text { BW/d for patients with acute and chronic renal failure } \\
\text { without renal replacement therapy. }\end{array}$ & Weak \\
\hline $\begin{array}{l}\text { Micronutrients and } \\
\text { other nutrients } \\
\text { requirements }\end{array}$ & $\begin{array}{l}\text { We suggest supplementing malnourished or at-risk medical inpatients on oral nutrition with multivitamins and } \\
\text { multiminerals to reach the recommended dietary allowance for micronutrients, thereby correcting or preventing } \\
\text { deficiencies. However, an individual assessment of patients remains crucial to specifically correct deranged } \\
\text { values of micronutrients. }\end{array}$ & Weak \\
\hline $\begin{array}{l}\text { Additional oral } \\
\text { supplementation }\end{array}$ & $\begin{array}{l}\text { ONS should be used in addition to hospital meals ideally adapted to individual preferences, to meet nutritional } \\
\text { requirements and improve outcomes of malnourished or at-risk medical inpatients. Fortification of meals and } \\
\text { providing patients with between-meal snacks should be at least equally part of the strategy to supplement intakes. }\end{array}$ & Strong \\
\hline \multirow[t]{2}{*}{$\begin{array}{l}\text { Route, monitoring } \\
\text { and reassessment }\end{array}$} & $\begin{array}{l}\text { Enteral tube feeding, ideally maintaining some oral food intake, should be implemented in medical inpatients } \\
\text { with or at-risk of DRM who could not reach } 75 \% \text { of their energy and protein targets (or consume more than } 75 \% \text { of } \\
\text { the food served daily) within } 5 \mathrm{~d} \text { of oral feeding and for whom clinical judgment predicted that oral nutrition } \\
\text { would not be sufficient to improve nutritional intakes. Intakes should be reassessed every } 24 \text { to } 48 \mathrm{~h} \text {. }\end{array}$ & Strong \\
\hline & $\begin{array}{l}\text { We recommend starting parenteral nutrition with a minimal oral or enteral feeding when possible, if oral and/or } \\
\text { enteral nutrition is not possible or if at least } 75 \% \text { of energy and protein targets have not been reached during the } 5 \mathrm{~d} \\
\text { following the beginning of enteral nutrition. Intakes should be reassessed every } 24 \text { to } 48 \mathrm{~h}\end{array}$ & Strong \\
\hline
\end{tabular}

BW, body weight; d, days; DRM, disease-related malnutrition; ONS, oral nutritional supplements; NRS, Nutritional Risk Screening; REE, resting energy expenditure

Based on the available evidence, the NRS should be used in medical wards to identify patients at risk of malnutrition and start nutritional therapy in patients with a score of at least 3 points within $48 \mathrm{~h}$ post hospital admission. Yet, the NRS is not intended to establish the diagnosis of existing malnutrition. When possible, a full nutrition assessment (including an indepth evaluation of anthropometric, biochemical, clinical, and dietary information) should be performed in patients with an NRS $\geq 3$ to determine if the patient is truly malnourished, to understand the causes of malnutrition, and thus to support the development of a tailored nutrition care plan. The recently diagnostic criteria proposed by ESPEN may be considered [16]. On the other hand, uncertainty remains about whether or not atrisk medical inpatients receiving nutritional therapy will indeed benefit from this intervention. This topic is covered by the next question.

Question 2. In malnourished or at-risk medical inpatients, does nutritional therapy result in improved outcomes when compared with usual care?

Studies describing any type of nutritional therapy interventions (oral, enteral, or parenteral) in medical inpatients with or at-risk of DRM were considered.

From six studies extracted, 1 systematic review of 325 patients showed weight gain and improved health-related QoL (measured by St George's Respiratory Questionnaire) in patients with chronic obstructive pulmonary disease (COPD) receiving oral, enteral, or parenteral feeding versus control [17]. We found three RCTs, two of which confirmed positive effects of nutritional therapy on weight stabilization (31 randomized patients with alcoholic hepatitis fed by the enteral route) [18] and weight gain (29 patients with acute leukemia receiving dietary counselling) [19]. The third found no effect in 212 patients with various diseases receiving dietary counselling and tailored nutritional support [14]. In the same study, the intervention resulted in increased protein and energy intake. One very small nonrandomized trial from 1989 performed on eight patients with congestive heart failure treated with enteral feeding resulted in gain of lean body mass but loss of weight [20]. In the sixth study, a non-randomized trial of 273 patients with alcoholic hepatitis receiving high-calorie, high-protein supplements with oxandrolone versus low-calorie, low-protein supplements without the drug, reduction of mortality, severity of disease and malnutrition was observed [21]. None of the studies included demonstrated effects of nutritional therapy interventions on length of stay (LOS) [14] or prevention of infection [19].

Due to inconsistent results and/or the lack of well-designed high-quality evidence, some of the disease-specific guidelines we selected are not providing recommendations about nutritional therapy in malnourished or at-risk patients. Available recommendations, however, consistently support this practice to improve nutritional status. Nutritional therapy is also recommended to improve other outcomes in particular groups of patients (e.g., improve survival in liver failure or geriatric patients).

Based on the limited available evidence and recommendations found in selected guidelines, there is a good rationale that nutritional therapy should be considered in malnourished or atrisk medical inpatients for at least 5 to $7 \mathrm{~d}$ in order to improve nutrition-related outcomes. More studies are needed in this group of patients to better understand if other outcomes can be improved in general medical inpatients (e.g. clinical, health resources and patient-centered outcomes).

\section{Energy and protein requirements}

Question 3. In malnourished or at-risk medical inpatients, should the gold-standard method indirect calorimetry be used to determine individual energy requirements, when compared with predictive equations? 

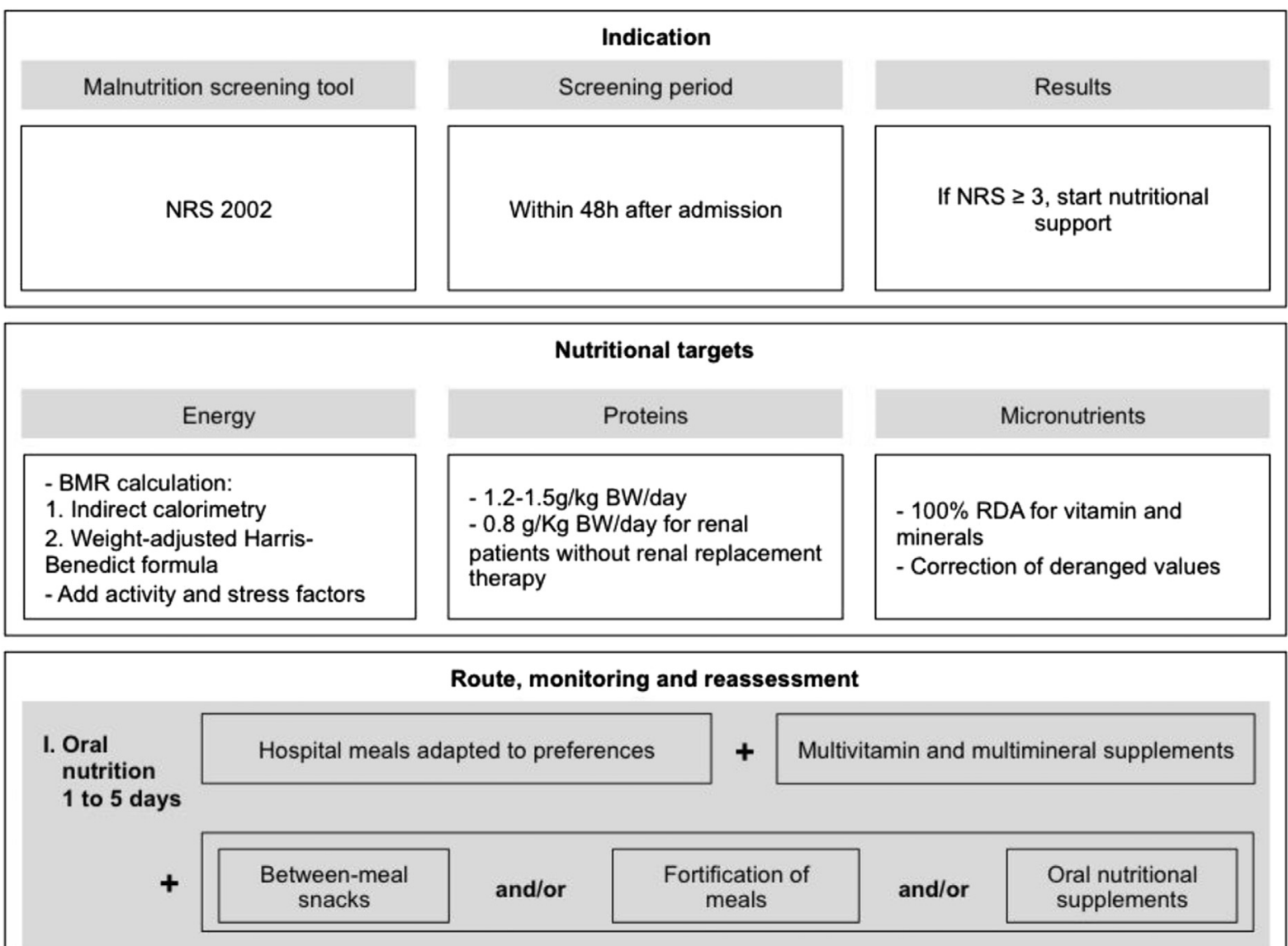

- Assessment of energy and protein intakes every $24-48 \mathrm{~h}$

- If $\geq 75 \%$ energy and protein targets reached, continue nutritional support

- If after 5 days $\geq 75 \%$ energy and protein targets are not reached (and anticipated not achievable with oral nutrition within the next $48 \mathrm{~h}$ ), start enteral nutrition

\section{Enteral nutrition \\ 1 to 5 days \\ Nasogastric or PEG tube + multivitamin and multimineral supplements \\ If enteral nutrition $\geq 1500 \mathrm{kcal}$, no multivitamin and multimineral supplements}

$(+)$

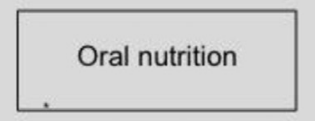

- Assessment of energy and protein intakes every $24-48 \mathrm{~h}$

- If $\geq 75 \%$ energy and protein targets reached, continue nutritional support

- If after 5 days $\geq 75 \%$ energy and protein targets are not reached (and anticipated not achievable with enteral nutrition within the next $48 \mathrm{~h})$, start parenteral nutrition

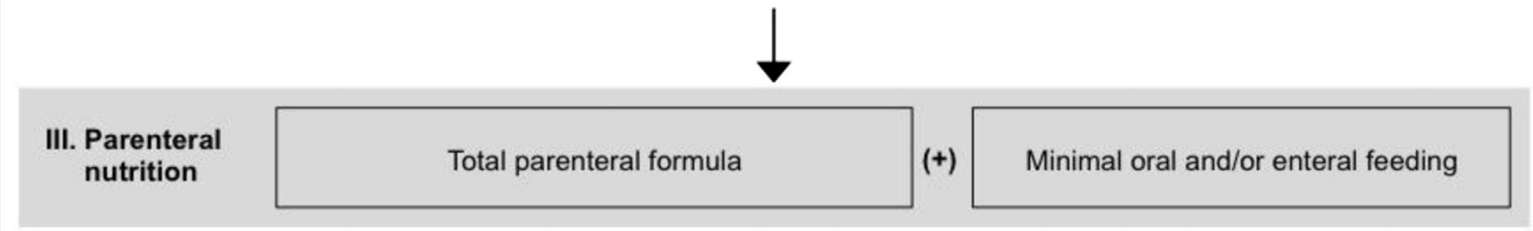

NRS = Nutritional Risk Screening; BW = body weight; RDA = recommended dietary allowance

Fig. 1. Nutritional algorithm: graphical representation of the suggested procedures. 
Energy requirements of hospitalized patients differ depending on total energy expenditure, which is largely affected by the body size, composition, as well as type and severity of disease. Indirect calorimetry is the gold standard method to determine total energy expenditure by measuring resting energy expenditure (REE) and including energy expenditure linked with physical activity and consumption of food $[22,23]$. However, the costs, availability, and practical considerations (e.g., requirement of trained personal to perform measurements or fasting periods before measurement) impose major barriers in using this method and might explain its underuse often observed in medical wards of hospitals [24]. The Harris-Benedict equation is more frequently used in hospitals to calculate REE and estimate caloric requirements, taking in consideration activity and stress factors. In under- and overweight patients, this equation does not enable precise calculation of REE. Using the Harris-Benedict equation with adjusted body weight (BW) calculated with the formula adjusted BW $=($ actual BW - ideal BW) $\times 25 \%+$ ideal BW might improve its accuracy, although it is still unclear how to ideally adjust BW in patients with a body weight outside of the normal range [25].

We found eight studies among the guidelines assessing REE in groups of malnourished or at-risk medical inpatients with various acute illnesses (acute renal failure [26], cancer [27,28], ulcerative colitis [29], acute pancreatitis [30], alcoholic hepatitis [31,32], congestive heart failure [33]). Among them, we found six studies (four observational studies [27-30] and two non-randomized trials [31,32]), in which REE was measured by indirect calorimetry and compared to the value predicted by Harris-Benedict formula. The formula failed to accurately predict REE in all studies. In addition, of the eight studies extracted, four non-randomized trials showed an increase REE of $42 \%$ [26], 55\% [29], $6 \%$ [30], and 18\% [33] for inpatients, compared to healthy controls.

If recommendations given by ESPEN for energy intakes are different for each disease type, indirect calorimetry is invariably suggested as the method of choice to determine energy targets.

Because the total energy expenditure of malnourished or atrisk patients hospitalized in medical wards varies largely among this heterogeneous group, REE should be individually measured by indirect calorimetry to enable an accurate calculation of the energy requirements. However, when this method cannot be used, we suggest calculating REE with the body weight-adjusted Harris-Benedict formula as long as clinical judgement and experience is also used to determine the final caloric targets.

Question 4. In malnourished or at-risk medical inpatients, do increased protein intakes result in improved outcomes, when compared with usual care?

Protein needs are generally increased in case of illness and hospitalization as a compensation for higher protein breakdown and to limit loss of total body protein mass and malnutrition [34].

A total of six studies from the selected guidelines met our selection criteria and were included. One observational study of eight ulcerative colitis patients suggested that intakes of at least $1.4 \mathrm{~g} / \mathrm{kg}$ BW/d are necessary to achieve nitrogen equilibrium [29]. In another small sample of six HIV patients, parenteral feeding supplying at least $1.2 / \mathrm{kg} \mathrm{BW} / \mathrm{d}$ of protein enabled patients to reach a positive nitrogen balance [35]. Of four studies conducted on individuals with liver disease [36-39], two studies (one observational of 37 patients [36] and one non-RCT of eight patients [37]) showed that patients receiving hospital diet providing $1.2 \mathrm{~g}$ of protein $/ \mathrm{kg} \mathrm{BW} / \mathrm{d}$ achieved positive nitrogen balance. Improved physical condition was also found in the small
non-RCT [37]. One RCT of 36 patients found that oral diet providing $1.5 \mathrm{~g}$ of protein $/ \mathrm{kg} \mathrm{BW} / \mathrm{d}$ had no effect on mortality, complications, or nutritional status [38]. The fourth study, an RCT of 64 patients from 1985 showed that protein supplementation of $65 \mathrm{~g}$ /day resulted in a positive nitrogen balance, but higher complication rates and no effect on mortality [39]. It is however impossible to assess the amount of protein per kilogram of BW that those patients received. Consistent with our findings, most selected guidelines recommend higher protein intakes (at least $1.2 \mathrm{~g} / \mathrm{kg} \mathrm{BW} / \mathrm{d}$ ). If malnutrition is diagnosed, including in elderly individuals, the ESPEN recommended protein intakes are further increased to 1.2 to $1.5 \mathrm{~g}$ protein $/ \mathrm{kg} \mathrm{BW} / \mathrm{d}$.

Intakes of protein increased to at least $1.2 \mathrm{~g} / \mathrm{kg} \mathrm{BW} / \mathrm{d}$ should be provided to correct or prevent protein malnutrition in malnourished or at-risk medical inpatients. More studies are needed to draw conclusions about the clinical benefits of increased protein intake and optimal amounts to treat different diseases.

Detrimental effects of high protein consumption on kidneys have been demonstrated [40]. Defining the protein targets of patients with or at risk of DRM and with altered kidney function is challenging, particularly for elderly patients, whose protein needs are further increased, creating a paradox difficult to handle for clinicians. Interestingly, soy-based proteins might be less harmful for kidneys [41], although their use is still controversial and requires more RCTs to be implemented safely [42].

No study from the ESPEN guidelines for acute renal failure patients met our inclusion criteria because a large majority was performed on intensive care patients. Based on the recommendations found in ESPEN guidelines and clinical judgement, we suggest lowering the protein intake to 0.8 to $1 \mathrm{~g} / \mathrm{kg} \mathrm{BW} /$ day for at-risk or malnourished medical inpatients with acute and chronic renal failure without renal replacement therapy.

\section{Micronutrients and other nutrients requirements}

Question 5. In malnourished or at-risk medical inpatients, does the supplementation of vitamins, minerals, and/or other nutrients (e.g. n-3 fatty acids and branched amino-acids) result in improved outcomes, when compared with usual care?

Electrolytes and vitamins deficiencies are common in patients with or at-risk of DRM with acute diseases requiring hospitalization in medical wards [43]. Furthermore, overfeeding of those patients can result in refeeding syndrome, also creating or worsening micronutrient deficiencies. Providing patients with supplementation (such as multivitamin, multimineral, or micronutrient supplements) might help prevent or correct existing deficiencies. Due to their anti-inflammatory properties, n-3 fatty acids supplementation might also be beneficial in some hospitalized patients.

We found two studies investigating micronutrient supplementation in medical inpatients with or at risk of DRM. Both were recent RCTs studying acute pancreatitis patients for the effects of high-dose vitamin $C$ and vitamin $C$ in combination with selenium and n-acetylcystein, respectively. The first study was performed on 84 patients and showed increased recovery rate, improved cellular immune function as well as reduced rate of complications and LOS in the intervention group [44]. In the second study of 43 patients, vitamin $C$, selenium, and n-acetylcystein treatment did not improve organ function, mortality, and LOS and did not reduce oxidative stress [45]. Three other RCTs investigated the effect of n-3 fatty acids supplementation in oncology patients. In one study of 200 patients from 2003, supplementation resulted in weight gain, increased lean body 
mass, and improvement of QoL [46]. None of the two other RCTs of 60 and 30 patients conducted in 2003 and 1998, respectively, reported beneficial effects on weight and functional status $[47,48]$. Additionally, no effect could be detected on appetite, nausea, tiredness, overall sensation of well-being, caloric intake, lean body mass [47], or survival rates [48] on supplemented patients.

The supporting evidence regarding vitamins, minerals, or other nutrients' supplementation on outcomes is limited to particular groups of patients (pancreatitis and cancer) and nutrients (vitamin C and n-3 fatty acids). It is therefore difficult to extrapolate those findings to general medical inpatients. Based on recommendations found in most selected guidelines, we suggest supplementing malnourished or at-risk medical inpatients with multivitamins and multiminerals to reach the recommended dietary allowance for micronutrients, thereby correcting or preventing deficiencies. Patients fed with enteral nutrition are addressed in question 7. Furthermore, an individual assessment of patients is needed in order to specifically correct out-of-norm values of micronutrients. No recommendations for supplementation with other nutrients (e.g. n-3 fatty acids) can currently be made based on available evidence.

\section{Additional oral supplementation}

Question 6. In malnourished or at-risk medical inpatients, does additional oral supplementation (e.g. oral nutritional supplements (ONS) and fortified meals) result in improved outcomes, when compared with standard care?

We identified five studies that explored the effect of ONS in at-risk or malnourished medical inpatients (elderly with various acute illnesses) and one in patients hospitalized for an acute exacerbation of COPD.

In a Cochrane review from 2002, the subgroup analysis of "unwell" ( $n=1623)$ or "undernourished" $(n=854)$ elderly patients demonstrated beneficial effects of ONS on mortality reduction [49]. In a subsequent meta-analysis from the same author published in 2006 [50], supplementation of undernourished hospitalized elderly individuals reduced mortality and complications, improved nutritional status, but had no effect on LOS. Three other studies (RCTs) consistently found nutritional intake improvements and overall status of hospitalized elderly patients who received ONS [51-53]. Two of those studies [51,53] additionally reported improved functional status, and one also showed reduced risk of mortality, but no difference in LOS [51].

In a RCT conducted in 33 COPD patients, supplementation with ONS or extra snacks in addition to the hospital diet resulted in increased forced vital capacity, protein, and energy intakes, but no significant changes were observed in other functional and nutritional parameters.

None of these RCTs have analyzed data based on both protocol analysis and intention to treat analysis. Among the RCTs included in the systematic reviews, some studies reported that participants were excluded from the analysis because they felt unable to take the supplements, but the analysis of outcomes on an intention to treat basis was overall deficient. Poor compliance with ONS treatments may limit their effectiveness, although this is a parameter that is not always assessed. Moreover, other nutritional interventions such as serving smaller and fortified meals or between-meal snacks may also help improving the nutritional intakes of hospitalized patients, particularly in the elderly [54,55].

Given these findings and that the geriatric population represents a large proportion of patients hospitalized in medical wards, as well as the consistent recommendations among selected guidelines, ONS should be used in addition to hospital meals ideally adapted to individual preferences to meet nutritional requirements and improve outcomes of malnourished or at-risk medical inpatients. Fortification of meals and providing patients with between-meal snacks should be at least equally part of the strategy to supplement intakes.

\section{Route, monitoring, and reassessment}

Question 7. In malnourished or at-risk medical inpatients able to consume food orally, does enteral tube feeding result in improved outcomes when compared with oral nutrition?

Oral feeding constitutes the most physiological route of feeding to correct DRM, but it is not always sufficient to treat DRM and improve outcomes, especially in cases of acute illness.

The supporting evidence we found to determine the preferred way of feeding malnourished or at-risk medical inpatients is limited to one RCT [56] conducted in acute pancreatitis patients where only one outcome (pain relapse following oral or enteral refeeding) was measured and no difference was found between both groups [56]. No data addressing the question of how long oral nutrition should be implemented before starting enteral tube feeding were found within the selected ESPEN guidelines.

All selected guidelines recommend oral nutrition as the first route of feeding for nutritional therapy of malnourished or atrisk patients who are able to ingest food. When the nutritional requirements cannot be met via this route during the recommended 5 to $7 \mathrm{~d}$ (according to the majority of the guidelines, although this period can be extended to $8 \mathrm{wk}$ in chronic infectious diseases), enteral tube feeding is recommended. In most guidelines, the recommended route of feeding is a nasogastric tube or a percutaneous endoscopic gastrostomy, for example, when long-term tube feeding is required.

Based on ESPEN recommendations, on the observation that body weight stabilizes in patients able to reach $75 \%$ of their nutritional needs [57] and on our own clinical experience rather than on supportive data, enteral tube feeding, ideally maintaining some oral food intake, should be implemented in medical inpatients with or at-risk of DRM who could not reach $75 \%$ of their energy and protein targets (or consume more than $75 \%$ of the food served daily) within $5 \mathrm{~d}$ of oral feeding and for whom clinical judgment predicted that oral nutrition would not be sufficient to improve nutritional intakes. Intakes should be reassessed every 24 to $48 \mathrm{~h}$.

Depending on how long enteral tube feeding is foreseen, both nasogastric tube and percutaneous endoscopic gastrostomy are possible routes. Unless enteral tube feeding provides more than $1500 \mathrm{kcal} / \mathrm{d}$, a multivitamin and micronutrient supplementation is needed to cover micronutrient needs.

Question 8. In malnourished or at-risk medical inpatients who are not able to consume sufficient food, does parenteral nutrition result in improved outcomes when compared with enteral nutrition?

One meta-analysis compared enteral with parenteral nutrition in 263 medical inpatients with acute pancreatitis [58]. Enteral nutrition resulted in reduced incidence of surgical interventions and LOS, but no effects on mortality or noninfectious complications were observed.

The recommendations provided in all selected guidelines state that in patients with an intact gastrointestinal tract, 
parenteral nutrition should be seen as a last resource when patients cannot be fed sufficiently orally or enterally.

Although supportive evidence is missing, we also recommend starting parenteral nutrition with a minimal oral or enteral feeding when possible, if oral and/or enteral nutrition is not possible or if at least $75 \%$ of energy and protein targets have not been reached during the $5 \mathrm{~d}$ after the beginning of enteral nutrition. Intakes should be reassessed every 24 to $48 \mathrm{~h}$.

\section{Discussion}

The procedures for detecting and treating DRM suggested in the present study should not be considered as providing robust recommendations such as those developed in validated guidelines (ESPEN or from other societies) for several reasons:

1. Our suggestions were developed using evidence extracted from selected current ESPEN disease- and medical specialtyspecific guidelines (Table 1). Therefore, we relied on the studies identified and included by the authors of those guidelines rather than conducting a new systematic search of the literature, with the possibility that several studies potentially relevant to answering our clinical questions might have been missed. Moreover, the guidelines used as a source of evidence were updated for the last time at least $6 \mathrm{y}$ ago, which consequently resulted in the extraction of studies published until 2007. Studies conducted later than this were therefore not captured and not used as evidence behind our questions.

2. The methodological quality and potential biases of the studies we extracted from the selected guidelines were not reassessed and were not taken in consideration when analyzing their results. This may have led to over- or underestimation of the effects of the interventions on the analyzed outcomes.

3. Due to limited evidence found to answer our questions, the procedures we suggest are not only based on published studies, but also take in consideration the recommendations given in the ESPEN guidelines we selected, as well as expert opinions, based on the clinical experience of the members of our working group.

4. Although the procedures suggested in this report are intended to apply to any medical inpatient independent of underlying disease, they do not exempt clinicians from identifying particular groups of patients for which an adaptation is needed to ensure optimal, clinically and ethically sound nutritional support, such as in the management of acute pancreatitis or patients in terminal conditions. A uniform nutritional strategy suitable for all medical inpatients might also lack from precision and might lead to a less sensitive effect compared to a more targeted approach. Yet, due to the growing challenges of older and frail medical inpatients, a pragmatic and integrated approach may still be needed.

\section{Conclusion}

Although this work differs from validated guidelines, we were able to develop and provide practical and simple guidance to detect existing DRM as well as those patients at-risk of developing DRM and implement nutritional therapy in the heterogeneous population of medical inpatients. Our suggestions are summarized in Table 2 and also graphically represented in the form of a user-friendly nutritional algorithm (Fig. 1), which is currently used to provide nutritional therapy in medical wards of several Swiss hospitals as part of a large multicenter RCT.

While this RCT includes the heterogeneous medical inpatient population receiving nutritional therapy according to the herein described practical procedures, it should be noted that particular subgroups of patients requiring a specific nutritional therapy approach are excluded from the trial (e.g., pancreatitis, terminal patients), in accordance with the previously acknowledged limitation of this study.

\section{Acknowledgments}

Members of the Working Group: Dr. Lisa Bounoure, Dr. Filomena Gomes, Rebecca Fehr, Dr. Martina Bally, Isabel Pulvermüller, Manuela Deiss, Prof. Dr. Philipp Schuetz, Prof. Dr. med. Beat Mueller, Department of Endocrinology, Diabetes and Clinical Nutrition, University Department of Internal Medicine, Cantonal Hospital Aarau. Prof. Dr. Zeno Stanga, Department of Endocrinology, Diabetes and Clinical Nutrition, University Hospital Bern. Prof. Dr. Ulrich Keller, Endocrine Practice and University of Basel, Switzerland. Dr. Rémy Meier, Gastrocenter Obach, Solothurn, Switzerland. Dr. Peter Ballmer, Maya Ruehlin, Dr. med. Reinhard Imoberdorf Department of Internal Medicine, Kantonsspital Winterthur, Switzerland. Dr. Alexander Spielmann, Hospital Muri, Switzerland. Dr. Laurence Genton, University Hospital Geneva (HUG), Switzerland. Dr. Kristina Norman, Charité Medical University Berlin, Germany. Dr. Pauline Coti Bertrand, University Hospital Lausanne (CHUV), Switzerland. Dr. Christoph Henzen, Kantonsspital Luzern, Switzerland. Prof. Dr. Alessandro Laviano, University Hospital Roma, Italy. Prof. Dr. Stephan Bischoff, University of Hohenheim, Germany. Dr. Stéphane Schneider, University Hospital and University of Nice Sophia-Antipolis, Faculty of Medicine, France. Dr. Jens Kondrup, Rigshospitalet University Hospital, Blegdamsvej, Copenhagen.

\section{Supplementary data}

Supplementary data related to this article can be found at http://dx.doi.org/10.1016/j.nut.2016.01.019.

\section{References}

[1] Kubrak C, Jensen L. Malnutrition in acute care patients: a narrative review. Int J Nurs Stud 2007;44:1036-54.

[2] Schuetz P, Bally M, Stanga Z, Keller U. Loss of appetite in acutely ill medical inpatients: physiological response or therapeutic target? Swiss Med Wkly 2014; $144: w 13957$.

[3] Morley JE, Thomas DR, Wilson MM. Cachexia pathophysiology and clinical relevance. Am J Clin Nutr 2006;83:735-43.

[4] Barker LA, Gout BS, Crowe TC. Hospital malnutrition: prevalence, identification and impact on patients and the healthcare system. Int J Environ Res Public Health 2011;8:514-27.

[5] Pirlich MST, Norman K, Gastell S, Lubke HJ, Bischoff SC, Bolder U, et al. The German hospital malnutrition study. Clin Nutr 2006;25:563-72.

[6] Imoberdorf R, Meier R, Krebs P, Hangartner PJ, Hess B, Staubli M, et al. Prevalence of undernutrition on admission to Swiss hospitals. Clin Nutr 2010;29:38-41.

[7] Felder S, Lechtenboehmer C, Bally M, Fehr R, Deiss M, Faessler L, et al. Association of nutritional risk and adverse medical outcomes across different medical inpatient populations. Nutrition 2015;31:1385-93.

[8] Seiler W. Clinical pictures of malnutrition in ill elderly subjects. Nutrition 2001; 17:496-8.

[9] Felder S, Braun N, Stanga Z, Kulkarni P, Faessler L, Kutz A, et al. Unraveling the Link between Malnutrition and Adverse Clinical Outcomes: Association of Acute and Chronic Malnutrition Measures with Blood Biomarkers from Different Pathophysiological States. Ann Nutr Metab 2016;68:164-72.

[10] Schuetz P. "Eat your lunch!" - controversies in the nutrition of the acutely, non-critically ill medical inpatient. Swiss Med Wkly 2015;145:w14132.

[11] Casaer MP, Hermans G, Wilmer A, Van den Berghe G. Impact of early parenteral nutrition completing enteral nutrition in adult critically ill patients: a study protocol and statistical analysis plan for a randomized controlled trial. Trials 2011;12:21. 
[12] Bally MR, Blaser Yildirim PZ, Bounoure L, Gloy VL, Mueller B, Briel M, et al. Nutritional support and outcomes in malnourished medical inpatients: a systematic review and meta-analysis. JAMA Intern Med 2015;176:45-53.

[13] Kondrup J, Rasmussen HH, Hamberg O, Stanga Z. Ad Hoc ESPEN Working Group. Nutritional risk screening (NRS 2002): a new method based on an analysis of controlled clinical trials. Clin Nutr 2003;22:321-36.

[14] Johansen N, Kondrup J, Plum LM, Bak L, Norregaard P, Bunch E, Educational and Clinical Practice Committee, European Society of Parenteral and Enteral Nutrition (ESPEN). Effect of nutritional support on clinical outcome in patients at nutritional risk. Clin Nutr 2004;23:539-50.

[15] Kondrup J, Allison SP, Elia M, Vellas B, Plauth M. ESPEN Guidelines for Nutrition Screening 2002. Clin Nutr 2003;22:415-21.

[16] Cederholm T, Bosaeus I, Barazzoni R, Bauer J, Van Gossum A, Klek S, et al. Diagnostic criteria for malnutrition - An ESPEN Consensus Statement. Clin Nutr 2015;34:335-40.

[17] Ferreira IM, Brooks D, White J, Goldstein R. Nutritional supplementation for stable chronic obstructive pulmonary disease. Cochrane Database Syst Rev 2012;12:CD00998.

[18] Kearns PJ, Young H, Garcia G, Blaschke T, O’Hanlon G, Rinki M, et al. Accelerated improvement of alcoholic liver disease with enteral nutrition. Gastroenterology 1992;102:200-5.

[19] Ollenschläger G, Thomas W, Konkol K, Diehl V, Roth E. Nutritional behaviour and quality of life during oncological polychemotherapy: results of a prospective study on the efficacy of oral nutritional therapy in patients with akute leukemia. Eur J Clin Invest 1992;22:546-53.

[20] Heymsfield SB, Casper K. Congestive heart failure: clinical management by use of continuous nasoenteric feeding. Am J Clin Nutr 1989;50:539 44.

[21] Mendenhall CL, Moritz TE, Roselle GA, Morgan TR, Nemchausky BA, Tamburro $\mathrm{CH}$, et al. A study of oral nutritional support with oxandrolone in malnourished patients with alcoholic hepatitis: results of a Department of Veterans Affairs cooperative study. Hepatology 1993;17:564-76.

[22] Boullata J, Williams J, Cottrell F, Hudson L, Compher C. Accurate determination of energy needs in hospitalized patients. J Am Diet Assoc 2007; 107:393-401.

[23] McClave SA, Lowen CC, Kleber MJ, Nicholson JF, Jimmerson SC, McConnell JW, et al. Are patients fed appropriately according to their caloric requirements? JPEN J Parenter Enteral Nutr 1998;22:375-81.

[24] Haugen HA, Chan LN, Li F. Indirect calorimetry: a practical guide for clinicians. Nutr Clin Pract 2007;22:377-88.

[25] MacDonald A, Hildebrandt L. Comparison of formulaic equations to determine energy expenditure in the critically ill patient. Nutrition $2003 ; 19: 233-9$.

[26] Schneeweiss B, Graninger W, Stockenhuber F, Druml W, Ferenci P, Eichinger S, et al. Energy metabolism in acute and chronic renal failure. Am J Clin Nutr 1990;52:596-601.

[27] Knox LS, Crosby LO, Feurer ID, Buzby GP, Miller CL, Mullen JL. Energy expenditure in malnourished cancer patients. Ann Surg 1983;197:152-62.

[28] Dempsey DT, Feurer ID, Knox LS, Crosby LO, Buzby GP, Mullen JL. Energy expenditure in malnourished gastrointestinal cancer patients. Cancer 1984;53:1265-73.

[29] Klein S, Meyers S, O’Sullivan P, Barton D, Leleiko N, Janowitz HD. The metabolic impact of active ulcerative colitis. Energy expenditure and nitrogen balance. J Clin Gastroenterol 1988;10:34-40.

[30] Dickerson RN, Vehe KL, Mullen JL, Feurer ID. Resting energy expenditure in patients with pancreatitis. Crit Care Med 1991;19:484-90.

[31] John WJ, Phillips R, Ott L, Adams LJ, McClain CJ. Resting energy expenditure in patients with alcoholic hepatitis. JPEN J Parenter Enteral Nutr 1989;13:124-7.

[32] Madden AM, Morgan MY. Resting energy expenditure should be measured in patients with cirrhosis, not predicted. Hepatology 1999;30:655-64.

[33] Poehlman ET, Scheffers J, Gottlieb SS, Fisher ML, Vaitekevicius P. Increased resting metabolic rate in patients with congestive heart failure. Ann Intern Med 1994;121:860-2.

[34] Genton L, Pichard C. Protein catabolism and requirements in severe illness. Int J Vitam Nutr Res 2011;81:143-52.

[35] Selberg O, Suttmann U, Melzer A, Deicher H, Muller MJ, Henkel E, et al. Effect of increased protein intake and nutritional status on whole-body protein metabolism of AIDS patients with weight loss. Metabolism 1995;44:1159-65.
[36] Nielsen K, Martinsen L, Stilling B, Wikman B. Nutritional assessment and adequacy of dietary intake in hospitalized patients with alcoholic liver cirrhosis. Br J Nutr 1993;69:665-79.

[37] Swart GR, van den Berg JW, Van Vuure JK, Rietveld T, Wattimena DL, Frenkel M. Minimum protein requirements in liver cirrhosis determined by nitrogen balance measurements at three levels of protein intake. Clin Nutr 1989;8:329-36.

[38] Bunout D, Aicardi D, Hirsch S, Petermann M, Kelly M, Silva G, et al. Nutritional support in hospitalized patients with alcoholic liver disease Eur J Clin Nutr 1989;43:615-21.

[39] Calvey H, Davis M, Williams R. Controlled trial of nutritionan supplementation, with and without branched chain amino acid enrichment, in treatment of acute alcoholic hepatitis. J Hepatol 1985;1:141-51.

[40] Fouque D, Laville M, Boissel JP. Low protein diets for chronic kidney disease in non diabetic adults. Cochrane Database Syst Rev; 2006:CD001892.

[41] Azadbakht L, Shakerhosseini R, Atabak S, Jamshidian M, Mehrabi Y, EsmaillZadeh A. Beneficiary effect of dietary soy protein on lowering plasma levels of lipid and improving kidney function in type II diabetes with nephropathy. Eur J Clin Nutr 2003;57:1292-4.

[42] Bernstein AM, Treyzon L, Li Z. Are high-protein, vegetable-based diets safe for kidney function? A review of the literature. J Am Diet Assoc 2007; 107:644-50.

[43] Rady MY. Nutritional considerations in the intensive care unit. J Gastrointest Surg 2004;8:759.

[44] Du WD, Yuan ZR, Sun J, Tang JX, Cheng AQ, Shen DM, et al. Therapeutic efficacy of high-dose vitamin C on acute pancreatitis and its potential mechanisms. World J Gastroenterol 2003;9:2565-9.

[45] Siriwardena AK, Mason JM, Balachandra S, Bagul A, Galloway S, Formela L, et al. Randomised, double blind, placebo controlled trial of intravenous antioxidant therapy in severe acute pancreatitis. Gut 2007; $56: 1439-44$

[46] Fearon KC, Von Meyenfeldt MF, Moses AG, Van Geenen R, Roy A, Gouma DJ, et al. Effect of a protein and energy dense N-3 fatty acid enriched oral supplement on loss of weight and lean tissue in cancer cachexia: a randomised double blind trial. Gut 2003;52:1479-86.

[47] Bruera E, Strasser F, Palmer JL, Willey J, Calder K, Amyotte G, et al. Effect of fish oil on appetite and other symptoms in patients with advanced cancer and anorexia/cachexia: a double-blind, placebo-controlled study. J Clin Oncol 2003;21:129-34.

[48] Gogos CA, Ginopoulos P, Salsa B, Apostolidou E, Zoumbos NC, Kalfarentzos F. Dietary omega-3 polyunsaturated fatty acids plus vitamin E restore immunodeficiency and prolong survival for severely ill patients with generalized malignancy: a randomized control trial. Cancer 1998;82:395-402.

[49] Milne AC, Potter J, Avenell A. Protein and energy supplementation in elderly people at risk from malnutrition. Cochrane Database Syst Rev; 2002:CD003288.

[50] Milne AC, Avenell A, Potter J. Meta-analysis: protein and energy supplementation in older people. Ann Intern Med 2006;144:37-48.

[51] Potter J, Roberts M, McColl J, Reilly J. Protein energy supplements in unwell elderly patients-a randomized controlled trial. JPEN J Parenter Enteral Nutr 2001;25:323-9.

[52] McEvoy AW, James OF. The effect of a dietary supplement (Build-up) on nutritional status in hospitalized elderly patients. Hum Nutr Appl Nutr 1982;36:374-6.

[53] Volkert DHS, Oster P, Schlierf G. Nutritional support functional status in undernourished geriatric patients during hospitalization and 6-month follow-up. Aging (Milano) 1996;8:386-95.

[54] Odlund Olin A, Armyr I, Soop M, Jerstrom S, Classon I, Cederholm T, et al. Energy-dense meals improve energy intake in elderly residents in a nursing home. Clin Nutr 2003;22:125-31.

[55] Gall MJ, Grimble GK, Reeve NJ, Thomas SJ. Effect of providing fortified meals and between-meal snacks on energy and protein intake of hospital patients. Clin Nutr 1998;17:259-64.

[56] Pandey SK, Ahuja V, Joshi YK, Sharma MP. A randomized trial of oral refeeding compared with jejunal tube refeeding in acute pancreatitis. Indian J Gastroenterol 2004;23:53-5.

[57] Kondrup J, Bak L, Hansen BS, Ipsen B, Ronneby H. Outcome from nutritional support using hospital food. Nutrition 1998;14:319-21.

[58] Marik PE, Zaloga GP. Meta-analysis of parenteral nutrition versus enteral nutrition in patients with acute pancreatitis. BMJ 2004;328:1407. 